\title{
Estudo de Caso como Procedimento de Pesquisa Científica: Reflexão a partir da Clínica Fonoaudiológica
}

\section{Case Study as Scientific Research Procedure: Reflection from Clinical Work}

\author{
Laïs de Toledo Krücken Pereira*, $a$, Dalva Maria Alves Godoy ${ }^{b}, \&$ Denise Terçariol $^{c}$ \\ ${ }^{a}$ Universidade do Sul de Santa Catarina , ${ }^{b}$ Universidade do Estado de Santa Catarina \\ ${ }^{c}$ Universidade do Vale do Itajaí
}

\begin{abstract}
Resumo
O artigo tem por objetivo refletir sobre questões metodológicas e epistemológicas relativas à utilização do Estudo de Caso como estratégia de pesquisa científica. São apresentadas três modalidades de estudos de caso na área da fonoaudiologia, focalizando a seleção de caso a partir de análise estatística, o uso do arquivo clínico na pesquisa e a construção da teoria de clínica. Analisam-se vantagens, possibilidades, dificuldades e cuidados necessários à utilização da estratégia. Os resultados evidenciam a flexibilidade da estratégia relativamente à seleção dos casos, coleta, análise e interpretação dos dados, salientando sua versatilidade. Destaca-se a transitividade da estratégia por diferentes esferas de conhecimento, da atuação clínica à construção teórica e ao ensino, ressaltando seu papel na construção do conhecimento na área. Palavras-chave: Estudo de caso; Pesquisa qualitativa; Método de pesquisa; Clínica.
\end{abstract}

\begin{abstract}
The objective of this article is to consider methodological and epistemological questions concerning the use of case study as a strategy of scientific research. Focusing on case selection through statistics analysis, the use of clinical files in research, and the construction of clinical theory, three kinds of case studies in the area of speech pathology are presented. Advantages, possibilities, difficulties, and necessary cares concerning the use of the strategy are analyzed. The results point out to the flexibility of the strategy in terms of selection of cases, collection, analysis, and interpretation of data, stressing its versatility. From clinical performance to theoretical construction and education, the transition of the strategy through different spheres of knowledge is evident, which emphasizes its role in the construction of knowledge. Keywords: Case study; Qualitative research; Research methods; Clinique.
\end{abstract}

O Estudo de Caso é um procedimento utilizado habitualmente na intervenção clínica com objetivo de compreensão e planejamento da intervenção, destacando-se pela possibilidade de integração de diferentes técnicas e campos do conhecimento. Nessa condição, o conhecimento teórico é dirigido ao individual e ao particular, em um autêntico ato de 'debruçar-se sobre o leito', o que, etimologicamente, encontra-se presente na palavra clínica, conforme aponta Barbier (1985). O autor refere também o significado "procedimento de observação direta e minuciosa", relacionado ao termo (p. 45) e à condição de a clínica incluir a exploração e compreensão dos significados presentes nas ações do sujeito.

Para Barbier (1985), a clínica representa conceito-chave pela condição de se situar no encontro entre a ciência fundamental e a ciência aplicada com relação ao homem. O autor propõe a valorização do espaço clínico como espaço científico, enfatizando sua característica fundamen-

*Endereço para correspondência: Rua Eduardo Nicolich, 33, Apto. 602, Agronômica, Florianópolis, SC, Brasil, CEP 88025-530. Tel.: (55) 4832049164 , (55) 4899338058

E-mail: laiskpereira@gmail.com tal de sensibilidade ao que é ambíguo, ao duplo sentido e ao hipercomplexo. Neste sentido, a clínica pode ser vista além de área específica de atuação como uma abordagem ou forma de olhar, como apontam Costa e Brandão (2005) em suas considerações sobre a possibilidade de construção de novas formas de atuação que se sustentem numa forma ampla de concepção de clínica.

A clínica configura-se como um precioso e particular espaço de conhecimento, semelhantemente a um laboratório (embora sem a possibilidade de controle dos elementos interferentes), no qual a todo momento se testam e se constroem hipóteses. Nesse espaço se confrontam teoria e realidade, hipóteses e soluções por vezes inesperadas e desconhecidas, no embate cotidiano de superação de dificuldades e buscas por melhores condições de vida. Em tal espaço, afirma Souza (2000), a prática não se configura como aplicação de teorias, pois a imprevisibilidade e o acaso dos encontros exigem que se produza e se opere sobre as teorias, originando novos vetores de teorização.

A fonoaudiologia focaliza o homem enquanto sujeito comunicante, sendo seu campo epistemológico "neces- 
sariamente multidisciplinar e interdisciplinar", como aponta Severino (1996, p. 24). Destaca ele que, como ciência aplicada, a relação teoria-prática, conhecimento-ação, é condição fundamental na construção de seu conhecimento específico. O estudioso, aliás, enfatiza o papel da prática na produção de conhecimento de qualquer área científica, bem como o caráter complexo da prática humana, que é ao mesmo tempo técnica, clínica, social e pedagógica.

A construção do conhecimento científico nas áreas que, como a fonoaudiologia, têm a clínica como referência, demanda visão integradora e múltipla, que possibilite apreender seu objeto de estudo em sua complexidade, o que implica visão abrangente sustentada por conhecimento oriundo de diferentes áreas (Minayo, 2004). Ao constituir origem e destino de formulações teóricas, a clínica se configura como condição fundamental na constituição do objeto de conhecimento da área, delimitando seu espaço científico (Cunha, 2000). O espaço clínico, ao mesmo tempo de utilização e de produção de conhecimento, necessita assim de procedimento particularmente flexível e capaz de respeito e apreensão de seus múltiplos desdobramentos a fim de tranformar-se em conhecimento científico.

Este artigo tem por objetivo refletir sobre questões metodológicas e epistemológicas relativas à utilização do Estudo de Caso como estratégia de pesquisa científica em áreas do conhecimento que têm a clínica como espaço de ação. A partir dessa perspectiva, procede-se à análise de condições e possibilidades, vantagens e dificuldades relativas à aplicação do Estudo de Caso como procedimento de investigação científica, com a finalidade de avaliar as suas possibilidades de contribuição à construção do conhecimento científico.

Inicialmente será apresentada a revisão de literatura que ofereceu suporte às considerações teóricas relativas à constituição do conhecimento científico, seus pressupostos e método. A seguir, será examinado o Estudo de Caso como estratégia de investigação do ponto de vista teórico e metodológico, focalizando-se as condições específicas de utilização. Ao final, serão feitas considerações gerais sobre a utilização do Estudo de Caso como estratégia de pesquisa científica nas áreas que têm a clínica como campo de atuação.

\section{O Conhecimento Científico: Pressupostos e Método}

O conhecimento científico se caracteriza pela busca de uma ordem invisível, subjacente à forma das coisas, como destaca Alves (1985). Busca a natureza íntima das coisas, que é a mesma em meio à multiplicidade de suas manifestações, ou seja, o invisível no visível, o permanente no transitório, o universal no particular. A busca da compreensão do conhecimento humano em uma visão integradora é característica em particular das ciências ditas sociais, que têm como objeto de estudo alguém que também pensa sobre sua ação e o que lhe acontece, o que afeta seu comportamento, sua disposição e as condições que cria no meio em que vive.

Segundo Hegenberg (2001), o ser humano, para adaptar-se à 'circunstância' em que vive de forma a transformá-la em 'mundo', elabora 'interpretações' que conferem 'inteligibilidade' às coisas, permitindo a ação sobre elas em benefício próprio. O conhecimento advindo desse processo tem vários níveis. O mais básico deles é o do 'saber de' (knowledge of, connaître). Nesse nível predominam os sentidos e a percepção, sendo portanto variável no espaço e no tempo. O nível seguinte é o do 'saber como' (knowledge how). Há aqui a manipulação dos objetos, a existência em ação de um 'se ... então'. Também variável no espaço e no tempo, esse nível permite, entretanto, a utilização de esquemas. Dessa forma os atributos começam a ser abstraídos dos objetos e possibilitam a elaboração de classes e o relacionamento entre sistemas de referência. O nível do 'saber que' (knowledge that, savoir) é independente da experiência imediata. Transcende os limites, independe do espaço e do tempo e subordina-se a um sistema de significações que vai além do saber individual. Esse nível está relacionado à lógica universal, é o espaço no qual a precisão de raciocínio tem papel fundamental. Como ressalta o autor, os três tipos de conhecimento estão intimamente associados e nos acompanham ao longo da vida.

Nas ciências do homem, o rigor científico para cumprir devidamente seu papel tem que se adaptar às condições do seu objeto de estudo, uma vez que a 'dificuldade' não está nas teorias ou no método; está na natureza do objeto. $\mathrm{O}$ método, com a finalidade de garantir a condição específica do conhecimento científico, representada pela objetividade, surgiu no contexto das ciências naturais, com o empenho de Descartes, em 1673, em determinar as regras de todo conhecimento científico, sendo seu papel o de procurar a verdade nas ciências e o de bem conduzir a razão, como aponta Granger (1994). O rigor científico é, assim, expressão da preocupação com a cientificidade da pesquisa. Entretanto, a evolução do conhecimento científico mostrou que a excessiva exigência de rigor científico pode restringir a construção do conhecimento. $\mathrm{O}$ zelo por tal rigor muitas vezes mostrou a necessidade de flexibilização dos procedimentos com relação aos ajustes ao objeto. Assim, na construção do conhecimento científico, deve prevalecer a condição de que "existem alguns métodos científicos, mas um espírito e um só tipo de visão propriamente científica" como afirma Granger (1994, p. 45).

Para Bachelard, o método há que ser considerado "uma astúcia de aquisição, um estratagema novo, útil na fronteira do saber" (1983, p. 122). Na concepção desse estudioso, é essa flexibilidade na mudança de método que pode garantir que a ciência se torne ainda mais metódica. Nas ciências sociais, o método deve subordinar-se à condição primordial de o objeto de estudo ser não apenas falante como pensante, modificando a si e ao seu 
meio conforme a interpretação que dá a sua circunstância. Minayo (2004), ao analisar diferentes aspectos do conhecimento na área da saúde, ressalta a necessidade de que o método na produção do conhecimento teórico incorpore a capacidade criadora e a experiência do pesquisador, que constituem a sua arte, de forma a relativizar e complementar o instrumental técnico. Essa capacidade do pesquisador reflete suas preocupações sociais e sua condição de perceber correlações multilaterais e em constante mutação presentes na realidade objetiva, nos limites da consciência possível. É essencial, portanto, que a escolha do método esteja condicionada pelo campo de investigação, considerado em sua riqueza de significados e no dinamismo da vida individual e coletiva como ponto inerente ao fenômeno de estudo.

Para Minayo (2002), a cientificidade deve ser considerada como uma idéia reguladora de alta abstração, ao invés de sinônimo de modelos e normas a serem seguidos. A autora ressalta que o trabalho científico caminha em duas direções, uma delas responsável pela elaboração de suas teorias, métodos, princípios e estabelecimento de resultados. A outra, precisa de liberdade para inventar e ratificar seu caminho, abandonando trajetos e revendo seu encaminhamento. Nesse trajeto, em que é necessária a aceitação tanto dos critérios de historicidade, como de colaboração, é fundamental que se reconheça que todo conhecimento é aproximado, fruto de construção. O procedimento científico é, assim, tanto a aquisição de um saber como o aperfeiçoamento de uma metodologia e a elaboração de uma norma, refere a estudiosa. Uma vez que a realidade social transcende em riqueza qualquer teoria, a autora considera a necessidade da utilização de instrumentos e teorias que possam "fazer uma aproximação da suntuosidade que é a vida dos seres humanos em sociedade" (Minayo, 2002, p. 15).

Viegas (1999), analisando o papel do método na construção do conhecimento, identifica os seguintes aspectos: o didático, ao guiar o pesquisador na busca de seu propósito; o econômico, ao indicar procedimentos estruturados e ordenados que evitarão a dispersão do pensamento e a perda de energia; e o pedagógico, ao apontar falhas que permitirão a correção de desvios e o alcance do sucesso na investigação. Outro aspecto a ser considerado, ressaltado por Nachmias e Nachmias (1996), é o da comunicação, pois o método possibilita compartilhar ou compreender uma experiência.

A estruturação interna da pesquisa, segundo Bruyne, Herman e Schoutheete (1977), configura um campo de forças de sua organização, formado entre os pólos epistemológico, teórico, morfológico e técnico. O pólo epistemológico tem a função de vigilância crítica, constituindo-se pelos modos de raciocínio que guiam a pesquisa. O pólo teórico tem a função de guiar a elaboração de hipóteses e a construção de conceitos, e é ele que vai se refletir na interpretação dos dados. Ao polo morfológico cabe compor a figura do objeto científico e cabe ao técnico, que deve poder ser confrontado à teoria, controlar a coleta de dados. Assim, são várias as dimensões e os aspectos que estão presentes no método científico e que, portanto, devem ser considerados na sua seleção e utilização com propósitos de pesquisa científica.

\section{O Estudo de Caso como Estratégia de Investigação Científica}

O Estudo de Caso caracteriza-se como o estudo profundo de um objeto, de maneira a permitir amplo e detalhado conhecimento sobre o mesmo, o que seria praticamente impossível através de outros métodos de investigação, afirmam Goode e Hatt (1973). Os autores caracterizam o Estudo de Caso como um meio de organizar dados e reunir informações, tão numerosas e detalhadas quanto possível, a respeito do objeto de estudo de maneira a preservar seu caráter unitário. A totalidade do objeto pode ser preservada através da amplitude e verticalidade dos dados, através dos diferentes níveis de análise, da formação de índices e tipos de dados, bem como da interação entre os dados observados e a dimensão temporal em que se dá o fenômeno.

Para Leonard-Baxton (1990), o Estudo de Caso é a história de um fenômeno, passado ou corrente, desenhado a partir de múltiplas fontes de evidência, nas quais se incluem dados obtidos tanto em observações diretas e entrevistas sistemáticas, como em arquivos públicos ou privados. Cada fato relevante para o conjunto de eventos descritos no fenômeno é um dado potencial para o Estudo de Caso.

Segundo Triviños (1987, p. 133, grifo do autor), o Estudo de Caso "é uma categoria de pesquisa cujo objeto é uma unidade que se analisa aprofundadamente". Esta unidade deve ser parte de um todo e ter realce, isto é, ser significativa e por isso permitir fundamentar um julgamento ou propor uma intervenção. $O$ autor considera ainda que o Estudo de Caso orienta a reflexão sobre uma cena, evento ou situação, produzindo uma análise crítica que leva o pesquisador à tomada de decisões e/ou à proposição de ações transformadoras. Conforme o autor, o Estudo de Caso caracteriza-se por sua natureza, uma vez que pode ter por objeto determinada comunidade, ou a história de vida de uma pessoa ou um processo terapêutico. Caracteriza-se também por sua abrangência, dado que a complexidade do estudo está determinada pelo referencial teórico que orienta o pesquisador. Ressalta, ainda, que a situação a ser estudada não pode ser isolada do seu contexto, pois o Estudo de Caso deve ser realizado com vistas a promover uma análise do contexto e dos processos envolvidos no fenômeno em estudo, considerando-se que o interesse do pesquisador deve ser com respeito à relação fenômeno-contexto.

Triviños (1987) aponta o Estudo de Caso como possivelmente o mais relevante dos tipos de pesquisa qualitativa. Refere a possibilidade de utilização do Estudo de Caso na pesquisa quantitativa, embora o considere pouco adequado à quantificação das informações. $\mathrm{O}$ autor 
identifica diferentes formas de Estudo de Caso, entre as quais os históricos-organizacionais, observacionais, de história de vida, de uma comunidade, de análise situacional (referentes a eventos específicos, como uma greve de estudantes) e microetnográficos (referentes a aspectos específicos de uma realidade maior, como o comportamento das crianças durante o recreio escolar). Pode ainda assumir a forma de Estudos Comparativos de Casos (quando há o estabelecimanto de comparação entre dois ou mais enfoques específicos, descrevendo, explicando e comparando por justaposição e comparação dos fenômenos) ou de Estudos Multicasos (quando há a possibilidade de estudar dois ou mais indivíduos e não existe o objetivo de comparação).

Com referência à condução de um Estudo de Caso, não existe uma forma única. Várias técnicas de investigação podem ser combinadas tendo em vista o propósito da pesquisa. Essa condição de versatilidade, que é o grande trunfo do procedimento, constitui também o ponto fraco desse "parente pobre" entre os métodos de ciências sociais, considera Yin (2001, p. xi). Outras críticas, segundo o autor, compreendem: falta de rigor, influência do investigador, pouca base para generalizações e extensão do estudo e demanda de muito tempo para a sua conclusão. No entanto, muitas das restrições se referem a condições relativas ao uso ou ao preparo do pesquisador. Como ressalta Yin (2001), apesar de o Estudo de Caso parecer, para muitos, uma pesquisa fácil, ela é extremamente complicada, daí a necessidade da identificação das condições da investigação e do preparo do pesquisador. O Estudo de Caso é uma situação única em que se lida com inúmeras variáveis de interesse e não apenas com pontos de dados, por isso deve seguir um conjunto de procedimentos pré-especificados.

Apesar de freqüentemente o Estudo de Caso ser abordado como ferramenta exploratória, Yin (2001) o considera uma ferramenta explanatória. Para tanto, algumas condições devem ser atendidas. A primeira e mais importante condição é definir o tipo de pergunta da pesquisa. O Estudo de Caso, considerado dentro de suas características, é particularmente útil para responder perguntas do tipo 'como' e 'por que', pois possibilita um estudo aprofundado do fenômeno. Outra condição é a observação do tipo de controle que o pesquisador tem sobre os eventos e qual o enfoque dado por ele ao fenômeno. O Estudo de Caso é útil, ressalta Yin (2001), quando se quer investigar acontecimentos contemporâneos em que não se pode controlar comportamentos considerados relevantes.

A pesquisa experimental, em contrapartida, embora seja igualmente direcionada a responder questões de pesquisa 'como' e 'por que', objetiva o controle do contexto (Yin, 2001). Nela o fenômeno está, de certa forma, distinguível de seu contexto e é exigida atenção especial às variáveis que o influenciam. No Estudo de Caso, de forma distinta, fenômeno e contexto nem sempre estão discerníveis dentro do contexto da vida real. Neste procedimento se quer, deliberadamente, lidar com condições contextuais, pois se acredita que essas condições são altamente pertinentes ao fenômeno investigado. Além disso, na pesquisa experimental, a coleta de dados é rigorosamente controlada pelo experimentador, ao passo que no Estudo de Caso o pesquisador entra no mundo do indivíduo observando a atividade da vida real, o que não significa menor rigor na coleta e análise dos dados.

O Estudo de Caso baseia-se em várias fontes de evidências e, como qualquer outra estratégia de pesquisa, apóia-se nas proposições teóricas pré-estabelecidas para conduzir a coleta e a análise dos dados. Assim, a teoria serve como modelo para análise e comparação dos resultados e possibilita a 'generalização empírica'. Os resultados do Estudo de Caso possibilitam generalizações a proposições teóricas e não a populações, uma vez que o objetivo da pesquisa de Estudo de Caso é expandir e generalizar teorias. Por isso a estratégia do Estudo de Caso como método de pesquisa requer a apresentação rigorosa dos dados e a delimitação teórica prévia. A unidade teórica de análise do Estudo de Caso deve especificar as questões primárias de pesquisa. Essa seleção apropriada conferirá robustez ao estudo. O Estudo de Caso não é, portanto, uma forma de se coletar evidências, mas uma possibilidade de aprofundamento e compreensão do objeto de estudo, caracterizando-se como estudo intensivo de uma situação ou contexto específico (Yin, 2001).

É importante ressaltar que o Estudo de Caso como método de pesquisa se diferencia de sua aplicação no ensino, pois neste o objetivo é proporcionar uma discussão e debate entre os participantes do grupo. Diferencia-se também do uso clínico, em que serve a propósitos de diagnóstico ou de intervenção. Assim, o uso clínico ou didático comporta recortes diferentes dos do âmbito da pesquisa científica. Na pesquisa, o Estudo de Caso se destaca sobretudo por manter a visão unitária do objeto de estudo em seu contexto, podendo integrar diferentes perspectivas disciplinares e diferentes técnicas investigatórias.

Para assegurar a condição de cientificidade do Estudo de Caso, é fundamental considerar vários aspectos que podem constituir pontos frágeis. Merecem particular atenção: a seleção dos casos, a coleta e o registro de dados, sua análise e a interpretação, bem como o planejamento e o preparo do pesquisador.

Do ponto de vista da pesquisa científica, pode-se destacar a flexibilidade do Estudo de Caso como uma de suas características. Segundo Tellis (1997), os Estudos de Caso são análises que incorporam várias perspectivas simultaneamente. A coleta de dados, as questões de pesquisa e as unidades de análise não podem seguir um padrão fixo como acontece na pesquisa experimental.

A sustentação teórica é aspecto fundamental no Estudo de Caso, que, "em sua particularidade, só pode aspirar à cientificidade integrado num processo de pesquisa global onde o papel da teoria não é deformado, onde a crítica epistemológica dos problemas e dos conceitos não 
é negligenciada" (Bruyne et al., 1977, p. 227). Para se evitar esse risco, afirmam os autores, é necessário que os Estudos de Caso não se limitem a descrições, por mais completas que sejam, mas que sejam orientados por hipóteses, apoiados em conceitos e que a coleta de dados seja dirigida por um esquema teórico. O referencial teórico se reflete na análise dos dados, considerada outro ponto delicado. Segundo Krippendotff (1980, citado por Lüdke \& André, 1986), a análise dos dados deve seguir técnica de pesquisa adequada, de forma a possibilitar a realização de inferências dos dados que sejam válidas para o seu contexto e que possam ser replicáveis. Essa concepção ressalta a diversidade possível de formas e ângulos através das quais a análise pode ser realizada e também os diferentes enfoques a que essa análise pode estar subordinada.

Considerando a importância do Estudo de Caso como método de investigação e sua importância para o campo das ciências humanas e sociais, em que fenômeno e contexto estão firmemente imbricados, a seguir se apresentam algumas reflexões relativas a situações específicas de utilização do Estudo de Caso. A primeira examina a possibilidade de seleção de Estudo de Caso a partir de pesquisa quantitativa. A segunda expõe a análise de casos clínicos como procedimento de pesquisa em Estudo de Caso documental. A terceira tece considerações sobre a importância do Estudo de Caso na construção da teoria de clínica. Os três tipos de estudos comentados são oriundos da Fonoaudiologia, área de atuação das autoras. Ressalta-se que o Estudo de Caso, ao permitir a integração do ponto de vista de diferentes áreas disciplinares, orienta-se a uma visão que, contrapondo-se à tendência de fragmentação e disjunção do conhecimento científico, tende à preservação da condição de complexidade do ser humano, valor fundamental na perspectiva de Morin (2000).

\section{A Seleção de Caso a Partir de Análise Estatística}

O Estudo de Caso se caracteriza, da mesma forma que a pesquisa experimental, como pesquisa explanatória, pois, como ressalta Yin (2001), busca responder às questões 'como' e 'por que', mas diferencia-se dela por não objetivar o controle do contexto. A pesquisa experimental trabalha com uma amostra representativa da população e objetiva o controle do contexto de ocorrência do fenômeno. Nela as variáveis que provavelmente influenciam o fenômeno são isoladas e manipuladas pelo pesquisador a fim de se observar os efeitos que essa variável produz sobre o objeto estudado. No Estudo de Caso, ao contrário, não há controle das variáveis, o que se quer deliberadamente é estudar o fenômeno em seu caráter unitário dentro de seu contexto, e a investigação está pautada em várias fontes de evidências presentes nesse contexto.

Os dados de uma pesquisa experimental são tratados estatisticamente e, freqüentemente, a partir da média da população estudada, os dados que estão acima ou abaixo de dois desvios padrão são desprezados, a fim de garantir uma amostra mais homogênea para análise. Esses resultados desprezados são denominados outliers, ou casos extremos (Woods, Fletcher, \& Hughes, 1986). Tomemos, como ilustração, uma pesquisa experimental que investigou a contribuição da consciência fonológica e a influência do método de alfabetização sobre o desenvolvimento inicial da leitura e da escrita ${ }^{1}$. O aporte teórico utilizado na pesquisa foi o modelo cognitivo de duplo processamento que considera a capacidade de análise fonológica uma habilidade fundamental para a aprendizagem da leitura e da escrita e, classicamente, utiliza a tarefa de leitura de pseudopalavras como importante instrumento de diagnóstico. Para a análise dos resultados dessa pesquisa experimental foram descartados os dados de três sujeitos que apresentavam médias abaixo de dois desvios padrão da média da amostra, ou seja, desprezaram-se os dados referentes ao desempenho em leitura de pseudopalavras de três casos extremos.

Esses três casos, no entanto, podem vir a constituir nova pesquisa objetivando responder 'como' e 'por que' não representam um evento dentro da média da população. Para essa nova pesquisa, a estratégia de Estudo de Caso é recomendada, uma vez que, ao considerar o fenômeno dentro de seu contexto de vida real, investiga-o em profundidade, o que permite um conhecimento amplo e detalhado sobre o mesmo (Goode \& Hatt, 1973). $\mathrm{Na}$ estratégia de Estudo de Caso, fatores que escaparam ao controle rigoroso da pesquisa experimental podem ser considerados e analisados.

Dessa forma, o Estudo de Caso a partir da análise estatística deve utilizar como unidade referencial de análise a da amostra inicial, e como teoria a que fundamentou a pesquisa experimental, para conduzir a coleta e a análise dos dados, como recomenda a metodologia do Estudo de Caso. Evidentemente, como o Estudo de Caso busca estudar o fenômeno dentro de seu contexto, outras variáveis, pertinentes ao fenômeno, devem ser investigadas, levando o pesquisador a observar fontes de evidência presentes na vida real. O procedimento de Estudo de Caso pode vir a confirmar ou refutar a teoria utilizada, ampliando, e aprofundando, o conhecimento sobre o assunto.

\section{O Uso do Arquivo Clínico com a Finalidade de Pesquisa: Um Procedimento}

O arquivo clínico, constituído pelo registro do atendimento prestado a pacientes, pode ser um precioso depósito de material para pesquisa. Esse arquivo é constituí- 
do por casos clínicos, cujos conteúdos podem ter sido obtidos a partir de diferentes técnicas com finalidade de intervenção. Numa pesquisa, tais casos passam a exigir diferente focalização e para isso precisam receber tratamento específico, que se inicia pela seleção do(s) caso(s) a partir do(s) objetivo(s) da pesquisa. Freqüentemente trata-se de dar nova vida a casos de arquivo morto.

Condição fundamental para o desenvolvimento desses estudos é a escolha de procedimento que dê conta dos objetivos da pesquisa, considerando o material disponível e sistematizando a coleta de dados. Esse aspecto é particularmente importante no estudo de caso múltiplo pela necessidade de padronização no tratamento dos dados. Numa pesquisa, o material do arquivo clínico é considerado documento, definido por Lüdke e André (1986) como qualquer material registrado que possa ser utilizado como fonte de informação. Os autores propõem para o estudo de documentos a técnica de leituras sucessivas, que consiste na realização de várias leituras até que o material seja considerado esgotado e que os dados se mostrem redundantes.

Esse foi o procedimento aplicado em um estudo de caso múltiplo realizado com o objetivo de estudar as condições referentes à dinâmica familiar em casos de distúrbios do desenvolvimento da linguagem ${ }^{2}$. A pesquisa foi desenvolvida a partir de material disponibilizado por uma clínica-escola de instituição do ensino superior localizada em grande centro urbano brasileiro, sendo constituído pela avaliação diagnóstica fonoaudiológica e psicológica realizada com crianças e seus pais. Os instrumentos da pesquisa foram roteiros referentes às entrevistas com os pais e às avaliações fonoaudiológicas e psicológicas, organizados a partir dos modelos clínicos e do marco teórico escolhido para a pesquisa. A análise, qualitativa, buscou relacionar os dados da história de vida dos sujeitos aos das avaliações fonoaudiológica e psicológica.

O procedimento adotado na pesquisa do material foi constituído pelas várias leituras que se mostraram necessárias no decorrer do processo, totalizando oito leituras sucessivas. As duas primeiras leituras foram gerais e tornaram viáveis a seleção dos casos e a aplicação dos roteiros, sendo selecionados sete casos. A terceira e a quarta leituras foram individualizadas e possibilitaram o relato de cada caso. A quinta e a sexta complementaram e esclareceram dados coletados. A sétima leitura derivou das necessidades de ajuste do foco narrativo e do acréscimo de dados que se fizeram necessários a partir desse ajuste. E a oitava leitura confirmou e exauriu os dados sob a perspectiva configurada no delineamento inicial da pesquisa.

${ }^{2}$ Pereira, L. T. K. (1995). Distúrbios do desenvolvimento da linguagem e dinâmica familiar. Tese de Doutorado nãopublicada, Curso de Pós-Graduação em Psicologia do Desenvolvimento Humano, Universidade de São Paulo, SP.
Durante esse processo, foram sendo efetivadas algumas modificações, entre as quais o ajuste do próprio objetivo, delineado mais nitidamente a partir das efetivas condições do material. O material assim constituído foi analisado em duas etapas. A primeira análise foi individual dos casos. Os resultados dessa análise, confrontados ao referencial teórico, levantaram uma série de considerações hipotéticas sobre os achados do conjunto geral dos casos. A segunda análise foi direcionada para o conjunto geral dos dados, com o objetivo de verificar possíveis pontos comuns, ou divergentes, entre os casos individuais. Em seguida, o conjunto dos dados colhidos foi reexaminado e organizado, o que resultou no aparecimento de temas e temáticas. Estes serviram de base para a organização de categorias, em torno das quais foram elaborados quadros de organização, cujo objetivo foi o de possibilitar a análise dos dados sob nova perspectiva. As categorias provieram basicamente do marco teórico, mas também se enriqueceram e melhor se delinearam ao longo do trabalho, de forma prevista por Lüdke e André (1986).

Para a determinação dessas categorias, foram considerados os critérios propostos por Guba e Lincoln (1981, citado por Lüdke \& André, 1986), isto é, as categorias devem refletir os propósitos da pesquisa e apresentar homogeneidade interna, heterogeneidade externa, inclusividade, coerência e plausibilidade. Nesse sentido as categorias criadas devem ser, ainda, mutuamente exclusivas e seu sistema de classificação deve ser passível de reprodução por outro juiz. A elaboração das categorias deu-se em várias etapas, de maneira bastante flexível, num esforço de melhor atender à especificidade do material e aos propósitos da pesquisa. Tal tarefa foi orientada pela preocupação com a sistematização e pela coerência do esquema de análise, organizado em confronto com o objetivo da pesquisa, conforme recomenda Lüdke e André (1986). Os diferentes itens resultantes dessa categorização foram analisados e relacionados entre si, com o propósito de identificar tanto elementos emergentes como relações e associações que pudessem ser consideradas pertinentes à questão em foco. Tal fase da análise se caracteriza como um processo divergente, integrado pelas estratégias de aprofundamento, ligação e ampliação (Guba \& Lincoln, 1981, citado por Lüdke \& André, 1986). O confronto teórico dos dados foi elaborado como etapa final da discussão dos resultados.

O procedimento para coleta e análise dos dados foi sendo construído durante sua própria evolução, condição esta também apontada por Lüdke e André (1986). O método mostrou-se consistente, adaptando-se às condições encontradas e orientando e sustentando o processo da pesquisa em suas diferentes fases: seleção, tratamento e análise dos dados e interpretação. Com isso, a técnica de leituras sucessivas utilizada no Estudo de Caso de material proveniente de arquivo clínico, apesar de laboriosa, mostrou-se efetiva, porque possibilitou a sistema- 
tização do procedimento da investigação, permitiu a padronização dos dados recolhidos e sua reelaboração em categorias, passíveis de interpretação e reflexão teórica, condição da cientificidade da estratégia de Estudo de Caso. Ressalta-se ainda a necessidade de criteriosa seleção do(s) caso(s) a partir do(s) objetivo da pesquisa(s) e a de consistente fundamentação teórica, que possibilite tanto a emergência de dados nas diferentes etapas do procedimento, como sua integração e interpretação, construindo a condição para o alcance do objetivo da pesquisa.

\section{O Estudo de Caso na Construção da Teoria de Clínica}

A Fonoaudiologia, assim como outras áreas que compartilham a clínica como espaço de atuação, é uma área do conhecimento cujo corpo teórico-metodológico é objeto de constante (re)construção. Essa afirmação pode ser justificada pela própria natureza da área que tem origem na atuação terapêutica. Ao se configurar como clínica, ela convoca o sujeito que a pratica a explicar as diferentes maneiras pelas quais seus pacientes se posicionam diante dos agravos à saúde. Nessa perspectiva, entra em cena não apenas a explicação dos quadros patológicos, mas também os modos que as pessoas têm de sentir, perceber, significar, representar e conduzir as suas vidas nos processos de adoecer: modos singulares e por muitas vezes imprevisíveis.

$\mathrm{Na}$ tentativa de explicar as peculiaridades de cada caso, ou melhor, as singularidades que na clínica se apresentam, os que realizam a ação de cuidar (fonoaudiólogos, psicólogos, psiquiatras, enfermeiros, entre outros) se orientam por teorias produzidas em diversos campos do conhecimento. Dessa busca por teorias que possam explicar os diferentes modos de adoecer (e não diferentes tipos de doenças), bem como que possam orientar os diferentes modos de cuidar, nascem indagações, que se bem formuladas resultam em perguntas de pesquisa. Dessas perguntas podem nascer novas teorias ou teorias complementares às já existentes. Afinal o conhecimento científico é sempre provisório e a relação entre teoria e prática é 'retroalimentar'.

Conforme nos diz Yin (2001), o Estudo de Caso deve ser utilizado quando se quer entender um fenômeno social complexo ou explicar ligações causais em intervenções ou situações da vida real que são complexas demais para tratamento através de estratégias experimentais ou de levantamentos de dados. O Estudo de Caso tem a finalidade de descrever um contexto de vida real no qual uma intervenção ocorreu, tendo indicação de utilização quando a pergunta de pesquisa se apresenta por meio de 'como' ou 'por que'.

Dessa forma, ao se entender o adoecer como um modo particular de se posicionar no mundo e que este modo demanda muitas vezes cuidados profissionais, entende- se o Estudo de Caso como ferramenta imprescindível para os que se preocupam em explicar o adoecer também como fenômeno social, cultural e psicológico.

\section{Considerações Finais}

Na situação clínica, o conhecimento oriundo da percepção direta e da intuição têm papel inegável no ajuste sensível e imediato, verbal e pré-verbal, do terapeuta à pessoa que é atendida. Nessa condição, esses conhecimentos, da ordem do 'saber de' (knowledge of, connaître) e do 'saber como' (knowledge how), se conjugam aos da ordem do 'saber que' (knowledge that, savoir), teóricos, independentes da experiência imediata e dos limites do espaço e do tempo, conforme a concepção de Hegenberg (2001). No espaço clínico, o estudo de caso constitui estratégia de busca de comprensão e de subsídios que pode transcender a atuação particular e os objetivos clínicos específicos, contribuindo para a construção do conhecimento científico.

O Estudo de Caso se configura como estratégia versátil que se ajusta à realidade através de múltiplas e diferentes técnicas e instrumentos. Essa flexibilidade pode ser constatada nos relatos apresentados, com referência à seleção dos casos, ou à coleta, análise e interpretação dos dados. Outra condição também relacionada à versatilidade é a possibilidade de trânsito entre as diferentes esferas de conhecimento: a da ação, referente à clínica; a da reflexão, relativa à construção teórica; e a do ensino, referente à formação e aprimoramento profissional.

$\mathrm{Na}$ construção da teoria, especialmente nas áreas da saúde, a compreensão está atrelada à intervenção. Conforme afirma Gutiérrez (2002, p. 5), "os sistemas, sejam naturais ou artificiais, materiais ou cognitivos, só adquirem uma significação humana na medida em que são assumidos pela ação, ou seja, incorporados à realidade concreta do mundo." A presente análise evidenciou que a valorização restrita do Estudo de Caso, 'primo pobre' dos procedimentos de pesquisa científica, é fruto tanto de uma visão limitada de ciência e metodologia como da inadequação da generalização do conhecimento obtido pelo estudo de um ou poucos casos. O Estudo de Caso só pode transcender do particular ao geral através da elaboração teórica, confirmando ou refutando conhecimentos já constituídos, e por este meio garantir sua condição de contribuição ao conhecimento científico. Essa condição salienta-se como a específica do Estudo de Caso como estratégia de construção do conhecimento científico, distinguindo-a de sua utilização para fins clínicos ou de ensino.

O Estudo de Caso oferece a possibilidade de alargamento da visão, apreendendo o indivíduo em sua integridade e em seu contexto. A estratégia permite a análise da dinâmica dos processos em sua complexidade, o que constitui sua condição específica de contribuição à construção do conhecimento científico. A abrangência de vi- 
são e flexibilidade peculiar dessa modalidade de investigação a caracteriza como instrumento coerente a uma visão sistêmica ${ }^{3}$ da ciência.

A visão referente à produção científica, inclusive a distinção das diferentes finalidades de um Estudo de Caso, assim como a consistência de uma pesquisa que tenha utilizado a estratégia metodológica de Estudo de Caso, está relacionada ao preparo do pesquisador nas diferentes dimensões presentes na elaboração de uma pesquisa, a saber, a epistemológica, a teórica, a morfológica e a técnica. Assim, para aqueles que têm a clínica como área de referência, considera-se fundamental que essa condição seja focalizada na formação profissional, que nos dias de hoje espera-se, mais que nunca, estar vinculada à produção do conhecimento e não somente à sua utilização.

\section{Referências}

Alves, R. (1985). Filosofia da ciência. São Paulo, SP: Brasiliense.

Bachelard, G. (1983). Epistemologia. Rio de Janeiro, RJ: Zahar.

Barbier, R. (1985). A noção de ciências humanas clínicas e as análises institucionais. Rio de Janeiro, RJ: Zahar.

Bruyne, P., Herman, J., \& Schoutheete, M. (1977). Dinâmica da pesquisa em ciências sociais. Rio de Janeiro, RJ: Francisco Alves.

Capra, F. (1987). O ponto de mutação. São Paulo, SP: Cultrix.

Costa, L. F., \& Brandão, S. N. (2005). Abordagem clínica no contexto comunitário: Uma perspectiva integradora. Psicologia \& Sociedade, 17(2), 33-41.

Cunha, M. C. (2000). Fonoaudiologia como lugar na ciência. In M. R. Freire (Ed.), Fonoaudiologia: Seminários de debates (pp. 3-6). São Paulo, SP: Roca.

Goode, W., \& Hatt, P. (1973). Métodos em pesquisa social. São Paulo, SP: Nacional.

Granger, G. G. (1994). A ciência e as ciências. São Paulo, SP: Editora da Universidade Estadual Paulista.

Gutiérrez, A. J. C. (2002). O problema científico: Construção formal ou delimitação no real. Tese de Doutorado nãopublicada, Curso de Pós-Graduação em Educação, Universidade Federal de Santa Catarina, Florianópolis, SC.

Hegenberg, L. (2001). Saber de e saber que: Alicerces da racionalidade. Petrópolis, RJ: Vozes.

Leonard-Baxton, D. (1990). A dual methodology for case studies: Synergistic use of a longitudinal single site with replicated multiple sites. Organization Science, 1(3), 248266.

Lüdke, M., \& André, M. (1986). Pesquisa em educação: Abordagens qualitativas. São Paulo, SP: EPU.

Minayo, M. C. S. (2002). Ciência, técnica e arte: O desafio da pesquisa social. In M. C. S. Minayo, Pesquisa social: Teoria, método e criatividade (pp. 9-29). Petrópolis, RJ: Vozes.
Minayo, M. C. S. (2004). O desafio do conhecimento. São Paulo, SP: Hucitec.

Morin, E. (2000). Ciência com consciência. Rio de Janeiro, RJ: Bertrand Brasil.

Nachmias, C., \& Nachmias, D. (1996). Research methods in social science. London: Arnolds.

Severino, A. J. (1996) A fonoaudiologia como ciência: Perspectivas epistemológicas. In M. C. Passos (Ed.), Fonoaudiologia: Recriando seus sentidos: Interfaces (pp.1327). São Paulo, SP: Plexus.

Souza, L. A. P. (2000). Métodos em fonoaudiologia: Princípios e técnicas. In M. R. Freire (Ed.), Fonoaudiologia: Seminários de debates (pp. 95-101). São Paulo, SP: Roca.

Tellis, W. (1997). Introduction to case study. The Qualitative Report, 3(2). Retrieved January 10, 2005, from http:// www.nova.edu/ssss/QR/QR3-2/tellis1.html

Triviños, A. N. S. (1987). Introdução à pesquisa em ciências sociais: A pesquisa qualitativa em educação. São Paulo, SP: Atlas.

Viegas, W. (1999). Fundamentos da metodologia científica. Brasília, DF: Editora da Universidade de Brasília.

Woods, A., Fletcher, P., \& Hughes, A. (1986). Statistics in language studies. Cambridge, MA: Cambridge University Press.

Yin, R. K. (2001). Estudo de caso: Planejamento e métodos. Porto Alegre, RS: Bookman.

${ }^{3}$ Por este termo se entende a condição de que: "Os sistemas são totalidades integradas, cujas propriedades não podem ser reduzidas às de unidades menores. Em vez de se concentrar nos elementos ou substâncias básicas, a abordagem sistêmica enfatiza princípios básicos de organização ... As propriedades sistêmicas são destruídas quando um sistema é dissecado, física ou teoricamente, em elementos isolados. Embora possamos discernir partes individuais em qualquer sistema, a natureza do todo é sempre diferente da mera soma de suas partes.” (Capra, 1987, p. 260).

Recebido: 11/05/2007

$1^{a}$ revisão: $16 / 06 / 2008$

$2^{a}$ revisão: $17 / 09 / 2008$

$3^{a}$ revisão: 03/12/2008

Aceite final: $04 / 12 / 2008$ 